\title{
Labyrinthe
}

28 | 2007 (3)

Des Juifs contre l'émancipation

\section{Paul Veyne, Quand notre monde est devenu chrétien (312-394)}

Paris, Albin Michel, 2007, 319 pages, 18 euros.

\section{Bruno Dumézil}

\section{OpenEdition}

\section{Journals}

Édition électronique

URL : http://journals.openedition.org/labyrinthe/2773

DOI : $10.4000 /$ labyrinthe. 2773

ISSN : 1950-6031

\section{Éditeur}

Hermann

\section{Édition imprimée}

Date de publication : 21 décembre 2007

Pagination : 157-160

ISBN : 978-2-9526131-5-6

\section{Référence électronique}

Bruno Dumézil, «Paul Veyne, Quand notre monde est devenu chrétien (312-394) », Labyrinthe [En ligne], 28 | 2007 (3), mis en ligne le 01 octobre 2007, consulté le 30 avril 2019. URL : http://

journals.openedition.org/labyrinthe/2773; DOI : 10.4000/labyrinthe.2773 


\section{QUAND NOTRE MONDE EST DEVENU CHRÉTIEN (312-394) de Paul Veyne*}

Bruno DuMÉZIL

bdumezil@u-paris10.fr

Depuis quarante ans, Paul Veyne s'amuse à poser à ses lecteurs des questions embarrassantes: les Grecs croyaient-ils à leurs mythes? L'amour conjugal serait-il une création tardive de l'Empire romain? Son dernier livre ne fait pas exception, puisqu'il revient à s'interroger sur les raisons profondes du triomphe du christianisme. Doit-on considérer que la nouvelle religion bénéficia, comme on le dit souvent, d'un milieu socioculturel porteur qui ne pouvait qu' assurer sa diffusion? Ou son succès est-il seulement le résultat d'un hasard historique, à savoir la conversion personnelle de Constantin en 312? Paul Veyne entreprend ici de nous démontrer que la seconde solution est vraisemblablement la bonne.

Son livre ne constitue pas pour autant un procès du despotisme impérial ou de l'opportunisme chrétien. Au contraire, Paul Veyne affirme en quatrième de couverture avoir écrit «le livre de bonne foi d'un incroyant qui cherche à comprendre comment le christianisme, ce chefd'œuvre de création religieuse, a pu entre 300 et 400, s'imposer à tout l'Occident». Car Paul Veyne affirme le génie du christianisme, qui seul aurait inventé un Dieu extraordinaire, à la fois un et multiple, généreux et sévère, historique et transcendant. Cette religion radicalement nouvelle aurait été soutenue par un «best-seller innovateur» (p. 57), la Bible, qui aurait assuré une diffusion de son message, restreinte mais de très haute qualité. Le précédent des religions orientales ou la profondeur de la seconde religiosité païenne, Paul Veyne n'y croit guère. Seul le christianisme proposait un système de pensée radicalement original (un

* Paris, Albin Michel, 2007, 319 pages, 18 euros. 
«polythéisme moniste», comme il le décrit à la page 41) et une structure d'encadrement efficace, à savoir l'Église autoritaire et prosélyte.

La foi dans le Christ aurait donc constitué, dès le $\mathrm{III}^{\mathrm{e}}$ siècle, une idée stimulante, appelée à séduire des esprits virtuoses. La nouvelle religion présentait certes une haute tenue morale qui lui permettait de séduire les pères de famille. Mais son public naturel était formé des intellectuels avant-gardistes et quelque peu révolutionnaires. Il était donc fatal que le christianisme inquiète, poussant même parfois les dirigeants à la répression. Toute mode un peu élitiste est naturellement appelée à être tenue à la marge et combattue par les autorités traditionnelles.

Par contre, une fois que le christianisme devint religion d'État, le message chrétien cessa rapidement d'être choquant. Les fonctionnaires s'y convertirent par carriérisme, et les masses populaires par imprégnation sociale. Paul Veyne récuse l'idée d'une persécution du paganisme; seuls les Juifs, selon lui, auraient profondément pâti du changement de religion d'État. Il doute également qu'une «idéologie» ait réellement soutenu le christianisme; si jamais elle a vraiment existé, ses résultats ne purent être que modérés. La source de conversion pour la grande majorité des populations occidentales devrait plutôt être recherchée dans l'obéissance traditionnelle que les peuples observaient envers leurs dirigeants et dans le pragmatisme de la nouvelle religion.

L'aspect le plus dérangeant de la démonstration est que, si le christianisme demeurait jusqu'en 312 une religion à la fois extrêmement minoritaire, globalement impopulaire et peu accessible au grand nombre, on peine à comprendre le tournant constantinien. Paul Veyne répond en mettant en avant l'individualisme de la décision et la sincérité du choix. Attention, cette sincérité n'eut pour autant rien d'une naïveté ou d'un élan immédiat du cœur. Paul Veyne envisage toute une série de motifs politiques ou intellectuels, souvent subtils, qui purent amener Constantin à embrasser la nouvelle religion. Toutefois, cette réflexion préliminaire n'aurait pas été réellement consciente. La conversion de Constantin aurait été un pur jaillissement de sincérité.

Lorsque l'on regarde maintenant la langue flamboyante et passionnée qui est celle de Paul Veyne dans ce livre, on ne peut manquer d'être marqué par le vocabulaire. Celui-ci est tantôt utilisé avec sérieux, tantôt avec ironie, mais il vient d'un fond bien identifiable. Le christianisme est une «avant-garde» (p. 124), l'Empire chrétien est dédouané de l'accusation de «totalitarisme» (p. 167), mais l'Église constitue bien 
un «parti unique». Le Fisc devient «une espère de Goulag» (p. 30) et la propagande impériale se donne des airs «de haut-parleurs de Démocraties populaires» (p. 234) aussi omniprésents qu'inefficaces. Soudainement, surgit un raccourci historique saisissant, puisque le rêve du pont Milvius, au cours duquel Constantin eut la révélation du signe de la croix en 312, appelle l'évocation de la rencontre de Lénine et Trotski, un certain soir d'octobre 1917 (p. 96-97). Et lorsqu'il s'agit de comprendre la signification que les contemporains donnaient à l'événement, le même parallèle s'impose : «Les bolcheviks ont été vainqueurs en 1917 parce qu'ils allaient dans le sens de l'histoire; Constantin a vaincu en 312 et en 324 parce qu'il allait dans le sens du Dieu qui le guidait» (p. 105-106).

On comprend alors mieux le propos. Paul Veyne lit la conversion de Constantin à la lumière de l'histoire des intellectuels français des années 1950, de ces hommes qui choisirent le marxisme à la fois par élitisme et par conviction. Toutefois, si l'historien choisit ce filtre de lecture, il le fait en toute bonne foi et souvent avec une autodérision gouailleuse, comme l'illustrent les multiples notes qui émaillent l'ouvrage. Cette jubilation de l'écriture ne dissimule pourtant pas l'individualité assumée du propos. Constantin ne peut qu'avoir été sincère, parce que Paul Veyne lui aussi affirme avoir été sincère en 1959, lorsqu'il s'est «converti» au parti communiste (p. 64). La figure du Christ devait être grandiose pour la upper middle class du IV siècle, car celle de Lénine apparaissait ainsi à la jeunesse dorée des Trente Glorieuses. Et Paul Veyne d'ajouter que lui aussi il a fait parfois des rêves étranges, qui l'aidèrent à synthétiser sa pensée (p. 128). Le sommeil de Constantin à la veille de la bataille du pont Milvius a pu produire le même type de résultats.

Quand notre monde est devenu chrétien est donc un livre subjectif, au sens le plus profond du terme, mais en toute connaissance de cause, sans chercher à tromper le lecteur ou à lui mentir sur le sens du propos. Certains ne manqueront pas d'être agacés par cet investissement du propos historique par l'ego de l'historien. Mais depuis Marrou et bien d'autres, personne ne croit plus à l'objectivité absolue, même pour l'étude de temps aussi reculés que ceux de l'Antiquité. Nous savons bien que nous instillons tous dans nos analyses un peu de nos croyances, de nos réflexes sociaux et même de notre vécu personnel. Et à bien y réfléchir, le livre de Paul Veyne a l'avantage de proclamer jusqu'à l'excès cet $a$ priori de l'écriture historique. 
En outre, l'ouvrage, en dressant un parallèle radical entre deux «conversions» éloignées de plus de seize siècles, permet aussi de réfléchir à la notion de sincérité. Il ne s'agit certainement pas de poser l'existence d'une pensée totalement désintéressée; Paul Veyne lui même n'y croit guère. Mais une telle approche permet d'apprécier le mode de perception de la décision à la fois par l'individu qui la prend et par ses contemporains. Paul Veyne juge que Constantin a été sincère, parce Lénine, Trotski, et pour finir lui-même et ses camarades des années 1950 ont été sincères. Il ne nie pas pour autant l'existence de calculs politiques, d'un déterminisme social ou d'effets de mode intellectuels. Simplement, il met en avant la «bonne foi » des acteurs à l'instant du choix.

Après tout, pourquoi pas? Les historiens des années 1990 et 2000 ne croient plus à cette sincérité des hommes, des motifs ou des sources. Leur génération, qui a vécu dans sa jeunesse la mort des idéologies, a appris à «déconstruire» le message des textes ou la mémoire des événements. Mais il serait exagéré de croire qu'il a pu toujours en être ainsi. Paul Veyne nous amène, par des moyens parfois violents, à admettre que la sincérité a elle aussi une histoire. On peut étudier une conversion en lui recherchant des raisons objectives; mais il est également possible, et probablement légitime, de considérer cette conversion d'un point de vue totalement subjectif, intime et presque mystique.

Les conversions et les repentirs d'une génération enthousiaste seraient-ils crédibles lorsque l'on parle des Français des Trente Glorieuses et contestables chez les Romains du IV siècle? Ne devons-nous pas parfois douter de nos propres doutes? Telles sont peut-être les véritables questions de ce livre, qui propose une relecture ébouriffante d'une des pages clefs de l'histoire des religions, mais qui surtout interroge l'historien en lui rappelant qu'il a lui aussi un passé. 